\title{
EDITORIAL
}

\section{BJO no século 21}

A partir de 2010 o Brazilian Journal of Oceanography passará a ser totalmente eletrônico. A impressão em papel cessará com o último número do volume 57, colocando o periódico definitivamente no século 21.

A divulgação eletrônica alcança continuamente público amplo e ávido por informação. Esse processo contribui para aumentar o impacto da pesquisa científica ao comunicar de forma rápida os resultados obtidos nos laboratórios. Em 2007 a entrada do Brazilian Journal of Oceanography (BJO) para o conjunto de revistas do portal SciELO contribuiu para dobrar seu índice de impacto medido já para o ano de 2008, passando de 0,23 (2007) para 0,48 (2008). Assim, o passo seguinte para ampliação da visibilidade foi transformar integralmente o processo de publicação do periódico para a forma de gerenciamento "on line", em consonância com os requisitos de nosso tempo. Desde a fase de submissão até a da publicação o autor terá informação sobre o andamento de seu manuscrito, podendo visualizar tudo com o clicar do "mouse". Ao invés de separatas os autores receberão o arquivo de seu trabalho em pdf, agilizando a distribuição e consequente divulgação.

O BJO trata da ciência oceanográfica de qualidade feita no Brasil e na América do Sul, sendo uma das 31 revistas brasileiras que têm agora seu fator de impacto calculado pelo ISI. Alcançar a excelência é nossa meta e para isso continuamos a apoiar a divulgação dos resultados que espelham boa parte do desenvolvimento científico que vem atingindo a ciência marinha em nosso continente. O BJO é uma revista com corpo editorial em todas as áreas da oceanografia, contando ainda com mais de uma centena de revisores brasileiros e estrangeiros, das mais diversas instituições de pesquisa e universidades.

Esperamos que essa medida incentive os pesquisadores a encaminhar seus bons trabalhos para publicação no Brazilian Journal of Oceanography, contribuindo para consolidar a ciência oceanográfica em nosso país e mostrá-la para o mundo.

Ana Maria Setubal Pires Vanin Editora-Chefe 